\title{
PROJETO DATAS AMBIENTAIS COMO ESTRATÉGIA PARA A SENSIBILIZAÇÃO ECOLÓGICA DA COMUNIDADE DE PORTO FERREIRA E REGIÃO
}

\author{
Andréia Luiza Baggio Rodrigues ${ }^{1}$ \\ Sonia Aparecida de Souza Evangelista ${ }^{2}$ \\ Ernesto Pedro Dickfeldt ${ }^{3}$
}

\begin{abstract}
RESUMO
Para a sensibilização da comunidade em relação ao meio ambiente e à biodiversidade local, a equipe do Parque Estadual de Porto Ferreira desenvolveu em 2014, entre os meses de janeiro e dezembro, o projeto Datas Ambientais, que consistiu na produção de textos descritivos e ilustrativos sobre datas comemorativas, conceitos e impactos ambientais, bem como sobre a importância de ações de conservação. Esses textos eram encaminhados mensalmente à comunidade escolar e divulgados em jornal eletrônico local. Para verificar a contribuição do projeto, foi elaborado na base Google Docs um questionário eletrônico com 10 questões, às quais os leitores do jornal Porto Ferreira Hoje responderam espontaneamente. Em 2014 o projeto divulgou 52 datas ambientais a fim de popularizar e socializar não só as datas em si, mas também informações e conteúdos específicos referentes a ações de educação ambiental formal e não formal, considerando o contexto local, conforme propõem as políticas públicas de educação ambiental. $O$ jornal eletrônico foi um espaço impar para o desenvolvimento do projeto, que foi avaliado como ótimo ou bom pela maioria, o que possibilitou a sua continuidade em 2015. O projeto atendeu às recomendações do Plano de Manejo da unidade em relação à divulgação da importância do parque e busca de apoio comunitário para a conservação da biodiversidade local, uma vez que o conhecimento tende à reflexão e às mudanças de comportamento e atitudes em relação ao meio ambiente.
\end{abstract}

PALAVRAS-CHAVE: Educação Ambiental não formal. Biodiversidade. Unidade de Conservação.

\section{ENVIRONMENTAL DATES PROJECT AS A STRATEGY FOR RAISING THE ECOLOGICAL SENSIBILITY OF THE COMMUNITY IN THE PORTO FERREIRA AREA.}

\author{
ABSTRACT \\ In order to raise the community's sensibility towards issues regarding the environment and the local \\ biodiversity, in 2014, from January to December, the Porto Ferreira State Park staff developed the \\ Environmental Dates project, which consisted in the production of descriptive and illustrative texts about

\footnotetext{
${ }^{1}$ Bióloga, Monitora Ambiental do Parque Estadual de Porto Ferreira - BK consultoria; baggio.andreia@hotmail.com

${ }^{2}$ Bióloga, PqC e Gestora do Parque Estadual de Porto Ferreira - IF/FF/SMA; sasouzapf@gmail.com.br

${ }^{3}$ Biólogo, Téc. Apoio à Pesquisa do Parque Estadual de Porto Ferreira; ernesto.dickfeldt@terra.com.br
} 
environment-related dates, concepts and impacts, as well as the importance of conservation actions. Those texts were then sent to the local school community and published in an electronic newspaper. To check the impact of the project, an electronic questionnaire consisting of 10 questions was made available on Google Docs and was answered freely by readers of the Porto Ferreira Hoje newspaper. In 2014 the project disclosed 52 environmental dates aiming to popularize and socialize not only the dates themselves but also specific information and contents related to formal and non-formal environmental education actions, taking into account the local context, as indicated by environmental education public policies. The electronic newspaper was a unique tool for the development of the project, which was assessed as excellent or good by most people, and therefore it continues to be carried out in 2015. It is also worth mentioning that the project has addressed the recommendations of the Management Plan of the unit in what refers to making people aware of the importance of the park and gaining their support for the conservation of the local biodiversity, since knowledge leads to reflection and to changes in behavior and attitude towards the environment.

KEY-WORDS: Non-formal environmental education. Biodiversity. Conservation Unit.

\section{PROYECTO FECHAS AMBIENTALES COMO ESTRATEGIA DE SENSIBILIZACIÓN ECOLÓGICA PARA LA COMUNIDAD DE PORTO FERREIRA Y REGIÓN.}

\section{RESUMEN}

Para la sensibilización de la comunidad en relación al medio ambiente y a la biodiversidad local, el equipo del Parque Estadual de Porto Ferreira desarrolló en 2014, entre los meses de enero hasta diciembre, el Proyecto Fechas Ambientales, que es la producción de textos descriptivos e ilustrativos sobre las fechas conmemorativas, conceptos e los impactos ambientales bien como la importancia y a las acciones de conservación. Esos textos eran encaminados mensualmente a la comunidad escolar y divulgados en periódico electrónico local. Para verificar la contribución del Proyecto, fue elaborado en base Google Docs, un cuestionario electrónico con 10 cuestiones, donde los lectores del periódico Porto Ferreira Hoje respondieron espontáneamente. En 2014, el proyecto divulgó 52 fechas ambientales a fin de popularizar y socializar no solo las fechas pero también informaciones y contenidos específicos como acción de educación ambiental formal y no formal, teniendo en cuenta el contexto local, como proponen las políticas públicas de educación ambiental. El periódico electrónico fue un espacio único para el desarrollo del proyecto, que ha sido valorado como óptimo y bueno por la mayoría, lo que posibilitó su continuidad en 2015. El proyecto atendió las recomendaciones del Plan de Manejo de la unidad, en relación con la difusión de la importancia del Parque y la búsqueda del apoyo de la comunidad, para la conservación de la biodiversidad local, una vez que el conocimiento lleva a reflejar y a los cambios de comportamiento y actitudes con relación al medio ambiente.

PALABRAS CLAVES: Educación Ambiental no formal. Biodiversidad. Unidad de Conservación. 


\section{INTRODUÇÃO}

A educação ambiental é definida como processos por meio dos quais o indivíduo e a coletividade constroem valores sociais, conhecimentos, habilidades, atitudes e competências voltadas para a conservação do meio ambiente. É um componente essencial e permanente da educação nacional, devendo estar presente, de forma articulada, em todos os níveis e modalidades do processo educativo, em caráter formal e não formal (BRASIL, 1999).

Segundo Fonseca (2005) a educação ambiental deve buscar integrar a educação formal e não formal, visando ações participativas e estabelecendo novas relações entre a natureza e ser humano.

Entende-se por educação ambiental formal as aquela desenvolvida no âmbito dos currículos das instituições de ensino públicas e privadas, desde a educação básica até a superior; enquanto que a não-formal às ações e práticas educativas voltadas à sensibilização, conscientização, mobilização e formação coletiva para proteção e defesa do meio ambiente e melhoria da qualidade da vida (BRASIL, 1999; SÃO PAULO, 2007).

Para Carvalho (2008) a educação é um processo de humanização, que ocorre na sociedade com a finalidade explícita de tornar os indivíduos em participantes do processo civilizatório e responsáveis por levá-lo adiante.

De acordo com Martins (2010) é extremamente notável a importância do contributo de cada pessoa para a preservação do ambiente e para isso é necessário sensibilizar a população de modo a inseri-la como possíveis agentes modificadores da atual situação ambiental.

Entre os princípios e objetivos da educação ambiental, destacam-se a sensibilização, a compreensão, a identificação das responsabilidades e o desenvolvimento de competências (SMITH apud SATO, 1995).

Nesse sentido, a sensibilização ambiental é um dos primeiros passos para a educação ambiental, configurando-se em estratégia para mudanças de atitudes em relação à proteção do meio ambiente.

Nas unidades de conservação gerenciadas pela Fundação Florestal, os processos educativos são embasados nos princípios estabelecidos pelas políticas nacional e estadual de educação ambiental; entre eles a compreensão integrada do 
meio ambiente em suas múltiplas e complexas relações, envolvendo aspectos ecológicos, históricos, psicológicos, legais, políticos, sociais, econômicos, científicos, culturais, tecnológicos e éticos; a participação comunitária ativa, permanente e responsável pela conservação e sustentabilidade, a democratização e a socialização das informações socioambientais (SILVA et al., 2014).

No Parque Estadual de Porto Ferreira - PEPF, unidade sob a gestão da Fundação Florestal, o subprograma educação ambiental tem os objetivos de propiciar ao indivíduo/comunidade uma visão mais abrangente da temática ambiental, através da qual, atitudes e habilidades são desenvolvidas visando a atuação crítica e participativa perante a conservação das áreas naturais protegidas; sensibilizar e conscientizar a comunidade sobre a importância da biodiversidade existente na Unidade, buscando o seu envolvimento e participação em ações para a sua conservação e valorização (TABANEZ et al., 2003).

Desde o início da década de 1990 a comunidade escolar e os grupos organizados foram o público alvo principal das atividades educativas no PEPF. Porém recentemente a unidade tem levado as suas ações para a comunidade em geral.

Considerando a frequente divulgação de datas relacionadas ao meio ambiente no formato de calendários e tendo em vista a importância de divulgar e socializar os conhecimentos sobre os conceitos relacionados às datas, em 2014 foi idealizado pela equipe do Programa de Uso Público do Parque Estadual de Porto Ferreira, o Projeto "Datas Ambientais" para a comunidade escolar e em geral.

\section{OBJETIVOS}

- Sensibilizar a comunidade utilizando a socialização e a divulgação de informações e conhecimentos relacionados ao meio ambiente e à biodiversidade local;

- incentivar a reflexão sobre as questões voltadas à conservação do meio ambiente por meio de divulgação de datas comemorativas, e

- divulgar a importância do PEPF para a conservação da natureza e da biodiversidade na região nordeste do estado de São Paulo. 


\section{METODOLOGIA}

O projeto adotou a metodologia de pesquisa bibliográfica sobre as datas comemorativas entre os meses de janeiro a dezembro relacionadas à diversos temas ambientais, agregando conhecimentos produzidos pelas pesquisas realizadas no Parque Estadual de Porto Ferreira com a produção de textos descritivos de 1 a 3 laudas com ilustrações e composto pelo histórico das datas, conceitos, principais impactos, importância e ações de conservação.

A Tabela 1 apresenta a relação de datas ambientais mensais.

Tabela 1: Datas Ambientais escolhidas entre os meses de janeiro á dezembro.

\begin{tabular}{|c|c|c|}
\hline Mês & Data & Comemoração \\
\hline \multirow[t]{2}{*}{ Janeiro } & 27 & Dia da Declaração Universal dos Direitos dos Animais \\
\hline & 31 & Dia do Engenheiro Ambiental \\
\hline \multirow[t]{3}{*}{ Fevereiro } & 02 & Dia Mundial das Zonas Úmidas \\
\hline & 06 & Dia do Agente de Defesa Ambiental \\
\hline & 22 & Dia da Criação do IBAMA \\
\hline \multirow[t]{3}{*}{ Março } & 01 & Dia do Turismo Ecológico \\
\hline & 21 & Dia Internacional da Floresta e Início do Outono \\
\hline & 22 & Dia Mundial da Água \\
\hline \multirow[t]{2}{*}{ Abril } & 15 & Dia da Conservação do Solo \\
\hline & 19 & Dia do Índio \\
\hline \multirow[t]{7}{*}{ Maio } & 03 & Dia do Pau-Brasil \\
\hline & 05 & Dia Mundial do Campo \\
\hline & 22 & Dia Internacional da Biodiversidade \\
\hline & 25 & Dia do Trabalhador Rural \\
\hline & 27 & Dia Nacional da Mata Atlântica \\
\hline & 29 & Dia do Geógrafo \\
\hline & 30 & Dia do Geólogo \\
\hline \multirow[t]{6}{*}{ Junho } & 03 & Dia Nacional da Educação Ambiental \\
\hline & 05 & Dia Mundial do Meio Ambiente e da Ecologia \\
\hline & 07 & Dia dos Catadores de Materiais Recicláveis \\
\hline & 17 & Dia de Combate á Desertificação e á Seca \\
\hline & 21 & Início do Inverno \\
\hline & 29 & Dia do Pescador \\
\hline \multirow[t]{2}{*}{ Julho } & 17 & Dia de Proteção ás Florestas \\
\hline & 28 & Dia do Agricultor \\
\hline
\end{tabular}


Agosto

09

14

Setembro

Outubro

Novembro
03

05

09
Dia Internacional dos Povos Indígenas e Dia Interamericano de Qualidade do Ar

Dia do Combate á Poluição

$$
\begin{gathered}
\text { Dia do Biólogo } \\
\text { Dia da Amazônia } \\
\text { Dia do Veterinário } \\
\text { Dia do Cerrado }
\end{gathered}
$$

Dia Internacional de Proteção á Camada de Ozônio e Dia Internacional para a Prevenção de Desastres Naturais

Dia da Árvore

Dia da Defesa da Fauna e Dia Mundial sem Carro

Início da Primavera

Dia mundial dos animais, Dia da Natureza e Dia do Paisagista Semana de Proteção á Fauna

Dia da Ave

Dia do Mar, Dia das Crianças e Dia do Agrônomo

Dia do Professor e Dia do Educador Ambiental

Dia da Cultura e da Ciência

Dia do Rio

Dia do Estatuto da Terra

Dia Internacional da Luta contra os Agrotóxicos

Dia do Jardineiro

Início do Verão

Dia da Esperança

No início de cada mês os textos produzidos são encaminhados via e-mail em PDF para o Departamento Municipal de Educação de Porto Ferreira, para as Diretorias de Ensino da Região de Pirassununga e de São João da Boa Vista e em versão doc. para o jornal eletrônico Porto Ferreira Hoje, divulgados no site http://www.portoferreirahoje.com.br/.

Para verificar a contribuição do Projeto, no mês de dezembro de 2014 foi elaborado um questionário eletrônico base Google Docs para as instituições de ensino e um para os leitores do jornal eletrônico Porto Ferreira Hoje (Anexo 1). 


\section{RESULTADOS}

Em 2014 o projeto divulgou 52 datas ambientais entre os meses de março à dezembro para o Departamento de Educação do Município de Porto Ferreira, Diretorias de Ensino da Região de Pirassununga e de São João da Boa Vista e para o jornal eletrônico Porto Ferreira Hoje.

A maioria das instituições de ensino não respondeu o questionário e esse fato pode estar relacionado às demandas de atividades de encerramento de ano letivo no mês de dezembro.

Os textos disponibilizados no Porto Ferreira Hoje foram acessados por diversas pessoas da comunidade e região, sendo que destas, apenas 20 responderam espontaneamente o questionário eletrônico, onde $70 \%$ tinham idade de 20 a 30 anos e 30\% com mais de 40 . Destes, $80 \%$ pertenciam ao município de Porto Ferreira e 20\% à Santa Rita do Passa Quatro.

Em relação à escolaridade, $80 \%$ possuía ensino superior, $10 \%$ ensino fundamental até a $4^{\mathrm{a}}$ série, seguido de $10 \%$ com ensino médio.

Quando perguntado como conheceram o projeto, a maioria $90 \%$ afirmou ter sido pelo site do Porto Ferreira Hoje, enquanto 10\% citaram amigos e familiares, indicando que o mesmo pode ser mais divulgado entre as pessoas.

Em relação ao acompanhamento do projeto, $40 \%$ declarou que o fazia desde o início, 20\% nos últimos quatro meses e 40\% a partir do mês de dezembro.

Quanto à opinião sobre o projeto, para $90 \%$ o mesmo foi considerado ótimo e para $10 \%$ bom, indicando a aceitação do mesmo.

Em relação ao conteúdo, $80 \%$ afirmou ser ótimo e $20 \%$ bom.

A linguagem utilizada foi considerada boa e didática por todos - 100\% e esse dado indica que a equipe conseguiu traduzir informações e conhecimentos ambientais específicos com linguagem adequada de fácil entendimento.

Quando perguntado se o projeto deveria continuar em 2015, houve uma concordância de 100\%, indicando a importância do mesmo, permitindo a socialização de conhecimentos ambientais.

Não houve nenhuma sugestão em relação ao projeto. 


\section{CONSIDERAÇÕES}

O projeto Datas Ambientais divulgou não só as datas comemorativas relacionadas aos diversos temas ambientais, mas também informações e conteúdos específicos na perspectiva de uma ação de educação ambiental formal e não formal, considerando o contexto local.

O jornal Porto Ferreira Hoje foi um espaço ímpar para o desenvolvimento do projeto, garantindo a democratização e a socialização das informações socioambientais para a comunidade do município de Porto Ferreira, conforme previsto na Política Estadual de Educação Ambiental.

O projeto foi bem avaliado pelos que responderam os questionários, indicando a sua aceitação e importância, possibilitando a sua continuidade em 2015.

O projeto atende às recomendações do Plano de Manejo da unidade, em relação à divulgação da importância do Parque e busca de apoio comunitário, uma vez que o conhecimento tende à reflexão, às mudanças de comportamento e atitudes em relação ao meio ambiente, principalmente à conservação da biodiversidade do Parque Estadual de Porto Ferreira.

\section{REFERÊNCIAS}

AZEVEDO, Rita Teixeira d'. Sensibilização Ambiental: importância e relação com a gestão ambiental. Naturlink, 2012. Disponível em: http://naturlink.sapo.pt/Natureza-e-Ambiente/Gestao Ambiental/content/Sensibilizacao-Ambiental-Importancia-e-Relacao-com-a Ambiental?bl=1\&viewall=true\#Go_1. Acesso em: 20 de fevereiro de 2014.

BRASIL. Lei n 9.795, de 27 de abril de 1999. Dispõe sobre a educação ambiental, institui a Política Nacional de Educação Ambiental e dá outras providências. Diário Oficial da União (D.O.U.), Brasília, 28/4/1999. Disponível em: http://www.planalto.gov.br/ccivil_03/leis//9795.htm. Acesso em: 26 de maio de 2014.

CARVALHO, Isabel Cristina de Moura. Educação Ambiental: a formação do sujeito ecológico. 4. Ed. São Paulo: Cortez, 2008. 255p. (Coleção Docência em Formação).

FONSECA, Vera Lúcia Bastos da.; COSTA, Maria de Fátima Barrozo da.; COSTA, Marco Antônio Ferreira da. Educação ambiental no ensino médio: mito ou realidade. Revista Eletrônica do Mestrado em Educação Ambiental, Rio Grande do Sul, v.15, p. 139-148, jul/dez/2005.

MARTINS, Margarida Quintela. Sensibilização e Educação ambiental. Disponível em: http://repap.ina.pt/bitstream/10782/352/3/Sensibiliza\%C3\%A7\%C3\%A30\%20e\%20Educa\%C3\%A7\% C3\%A30\%20Ambiental.pdf. Acesso em: 18 de fevereiro de 2014. 
SÃO PAULO. Lei ํo 12.780 de 30 de novembro de 2007. Institui a Política Estadual de Educação Ambiental. D.O.E., 1 dez 2007. Seção I, p. 1- 3.

SATO, Michele. Educação Ambiental. Ed. RIMA. São Carlos, SP. 2003. 66 p.

SILVA, Adriana Neves da et al. Programa de Educação Ambiental da Fundação Florestal (Doc. Interno).

TABANEZ, Marlene Francisca et al. Plano de Manejo do Parque Estadual de Porto Ferreira. São Paulo: $\mathrm{O}_{2}$ Estúdio Web, 2003. 1 CD-ROM. 


\section{ANEXO 1}

\section{Questionário do Projeto Datas Ambientais elaborado para leitores do Porto Ferreira Hoje.}

1. Idade.

( ) até 10 anos

( ) 10 a 20 anos

( ) 20 a 30 anos

( ) mais de 40 anos

2. Município que reside.
( ) Porto Ferreira
( ) Santa Rita do Passa Quatro
( ) Descalvado
( ) Pirassununga
( ) Santa Cruz das Palmeiras
( ) Outro

\section{Escolaridade.}

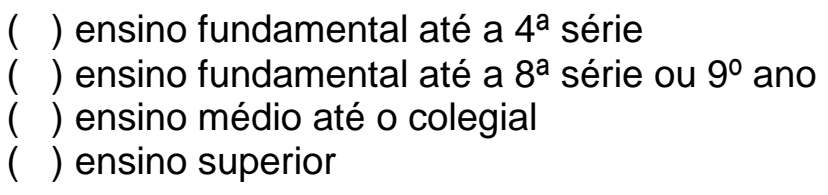

4. Como ficou sabendo do projeto Datas Ambientais?

( ) através do site Porto Ferreira Hoje

( ) por amigos e ou familiares

( ) pela escola

5. Acompanha o projeto desde quando?
( ) desde o início
( ) nos últimos 4 meses
( ) nos últimos 2 meses
( ) a partir desse mês

6. Sua opinião sobre o projeto Datas Ambientais:

( ) ótimo ( ) bom ( ) regular

7. Sua opinião sobre o conteúdo:

( ) ótimo ( ) bom ( ) regular

8. Sua opinião sobre a linguagem:

( ) muito técnica ( ) boa e didática

9. O projeto deve continuar em 2015 ?

( ) sim
( ) não
( ) sim com mudanças

10. Sugestões: 